\title{
Greenhouse Gas Emission Reduction Under The Kyoto Protocol: The South African Example
}

John Luiz, (Email: jluiz@uj.ac.za), University of Witwatersand, Johannesburg, South Africa Eugene Muller, University of Witwatersand, Johannesburg, South Africa

\begin{abstract}
Carbon dioxide $\left(\mathrm{CO}_{2}\right)$ emissions and its contribution to global warming has become an increasing concern to the international community. Although launched in 1997, the Kyoto Protocol only came into force in February 2005, with the goal to reduce greenhouse gas (GHG) emissions globally. This resulted in the establishment of a Clean Development Mechanism (CDM) which involves emissions in developing countries such as South Africa, giving them an opportunity to benefit financially when reducing GHG emissions voluntarily. The qualitative research approach used in this study gain inputs from experts in the CDM process in the South African environment so as to examine factors impacting on the viability of these projects. With the current outlook, this study suggests that there is a relatively high likelihood that the CDM would have the desired effect of reducing GHG emissions from existing South African industry and other developing countries given the incentive to do so.
\end{abstract}

Keywords: Kyoto protocol, greenhouse gas emission reductions, South African industry, sustainable development, developing countries

\section{Introduction}<smiles>[O]</smiles>

ver the past few decades, carbon dioxide pollution has become an increasing concern to the international community. During the last decade concern has grown over the continued rise in anthropogenic GHG emissions and the associated risk of climate change (Ranganathan and Bhatia 2003). Being a known greenhouse gas (which causes global warming), excessive quantities of carbon dioxide have been shown to cause a warming of the earth's surface by trapping solar heat within the earth's atmosphere (Carstanjen 2002).

This global warming, at least some of which may be due to past greenhouse gas emissions, has slowly raised the earth's temperature by between 0.6 and $1{ }^{\circ} \mathrm{C}$ over the past one hundred years. As a result of higher temperatures, the oceans' levels are rising, global weather patterns are changing, and ecosystems around the world are being affected (Houghton 2004). Six gases $\left(\mathrm{CO}_{2}, \mathrm{CH}_{4}, \mathrm{~N}_{2} \mathrm{O}, \mathrm{HFC}, \mathrm{PFC}\right.$, and $\mathrm{SF}_{6}$ ) have been classified as greenhouse gases (Stiles 2005a). Their effect on the environment, i.e. global warming potential, is stated in terms of $\mathrm{CO}_{2}$ equivalent $\left(\mathrm{CO}_{2} \mathrm{e}\right)$ in order to compare the effects of the different gases on the environment with each other.

Atmospheric pollution, including pollution by many oxides of sulphur and nitrogen, has been regulated for many years (even in developing countries such as South Africa). By contrast, greenhouse gases have until now received little attention from the authorities in developing countries, and even in countries where they do receive attention regulations, if any, are not as stringent as for some other pollutants. This is because, as so-called "global pollutants", greenhouse gases do not have a direct or measurable impact on the health of local populations, even though they may impact indirectly through changes in weather patterns, rising sea levels, etc. More critically, it is impossible to attribute such indirect impacts to a particular source, e.g. a particular factory or waste disposal site (Carstanjen 2004). 
Being a global problem, greenhouse gases can best be "regulated" and reduced through international actions - actions which provide incentives for those countries producing the largest amounts of these gases to reduce them in a cost-effective manner (Carstanjen 2006). This is the major rationale for the Kyoto Protocol, which provides a framework both for reductions in greenhouse gases by industrial or so-called Annex1 countries (the major source of these gases) and for participation in the process by developing or non-Annex 1 countries (some of which, like South Africa, are also significant sources of GHG emissions).

The purpose of this research is to determine whether the global efforts to reduce greenhouse gas (GHG) emissions through the ratification of the Kyoto Protocol, and more specifically its Clean Development Mechanism (CDM), are likely to reduce the amount of GHG emitted by existing South African industry in the next ten years. As the current legislation in South Africa does not specify any legal limit for GHG emissions, it is argued that a financial benefit is required to encourage companies to reduce their GHG emissions. A potential project to reduce $\mathrm{N}_{2} \mathrm{O}$ emissions from one of South Africa's nitric acid $\left(\mathrm{HNO}_{3}\right)$ plants will be referred to as an example of a Clean Development Mechanism (CDM) project that will reduce GHG emissions from South African industry. It will provide an example of the potential financial benefit to a company that reduces its GHG emissions, as well as illustrate the process a company needs to follow to obtain the benefit.

\section{Global Pressure To Reduce Greenhouse Gases}

Most scientists agree that if no steps are taken to slow down GHG emissions it is quite possible that GHG levels in the atmosphere will triple between now and the year 2100. The most direct result of this will be global warming of between 1.4 and $5.8{ }^{\circ} \mathrm{C}$ over the next 100 years (Carstanjen 2002). Scientific predictions are that climate change will adversely affect Africa. The IPCC predicts that climate change will exacerbate existing physical, ecological/biological, and socio-economic stresses on the African coastal zone. Extreme climate conditions will result in increased rainfall and floods in the Sahel region, with accelerated desertification and persistent drought in Southern Africa in the coming decades (Immink 2006).

According to Tyani et al. (2006), the greenhouse gas profile of South Africa is strongly related to its energy sector. South Africa consumes half of Africa's electricity, while constituting only $5 \%$ of its population. Likewise South Africa's GHG emissions are increasing - in 1990 it contributed 1.02\% of the total global GHG emissions, but by 1999 the figure had increased to $1.6 \%$.

\subsection{Why Is International Action Required?}

Increases in global GHG emissions have already brought changes to the earth's climate. Nine of the ten hottest years since 1860, when temperature records were first kept, occurred between 1990 and 2000 (Baumert and Kete 2002). Global surface temperature has increased by 0.3 to $0.6^{\circ} \mathrm{C}$ since the late $19^{\text {th }}$ century and by 0.2 to $0.3^{\circ} \mathrm{C}$ in the last 40 years.

The international community began attempts to address climate change in 1992 through the United Nations Framework Convention on Climate Change (UNFCCC). Countries around the world started to stand together to meet this challenge, with the overall objective of stabilising atmospheric GHG concentrations at safe levels.

\subsubsection{The Kyoto Protocol}

Although the 1992 convention was a good start, scientific evidence continued to accumulate, and by 1997 it had become clear that a more ambitious and mandatory reduction target was needed to control climate change (Baumert and Kete 2002). In December 1997, after two and a half years of intense negotiations, governments responded to the growing public pressure to reduce GHG emissions by adopting the Kyoto Protocol. This protocol is considered to be the most far-reaching agreement on environmental and sustainable development ever adopted. It introduced legally binding constraints on GHG emissions, but also introduced mechanisms aimed at cutting the cost of curbing emissions (Waller-Hunter 2002). 
The Kyoto Protocol is an immensely complex and far-reaching document, but its most significant impact is simple and straightforward: to create a market for reductions in greenhouse gases, i.e. for the "credits" resulting from these reductions. Like the 1987 Montreal Protocol, which aimed to reduce emissions of ozone-depleting substances through voluntary actions, the Kyoto Protocol calls on the countries of the world to work together to create a framework for achieving meaningful emissions reduction. Unlike the Montreal Protocol, however, the Kyoto Protocol is based largely on market mechanisms that are designed to do this rationally and at the least cost to both the polluter and society as a whole. A market mechanism enables the incorporation of the cost of an environmental abatement project into mainstream business decision making. Market mechanisms also allow companies flexibility in meeting their targets (Stiles 2005b).

Although launched in 1997, the Kyoto Protocol only came into force in February 2005, 90 days after it had finally been ratified by $55 \%$ of the original signatories, including countries responsible for more than $55 \%$ of the total emissions from the industrial country group (Annex1 countries). The Kyoto Protocol provides for a wide variety of solutions to climate change, including some which will assist countries (and companies) in reducing GHG emissions and some which will help them to "adapt" to the greater risk and uncertainty created by global warming (Waller-Hunter 2005).

Figure 1 tries to explain the logic of the Kyoto Protocol's intentions. A company that reduces its GHG emissions voluntarily would be able to earn CERs if the project is implemented in line with the Kyoto Protocol. Companies that exceed their GHG emission limits, on the other hand, could buy these CERs from those that have earned CERs - a win-win situation.

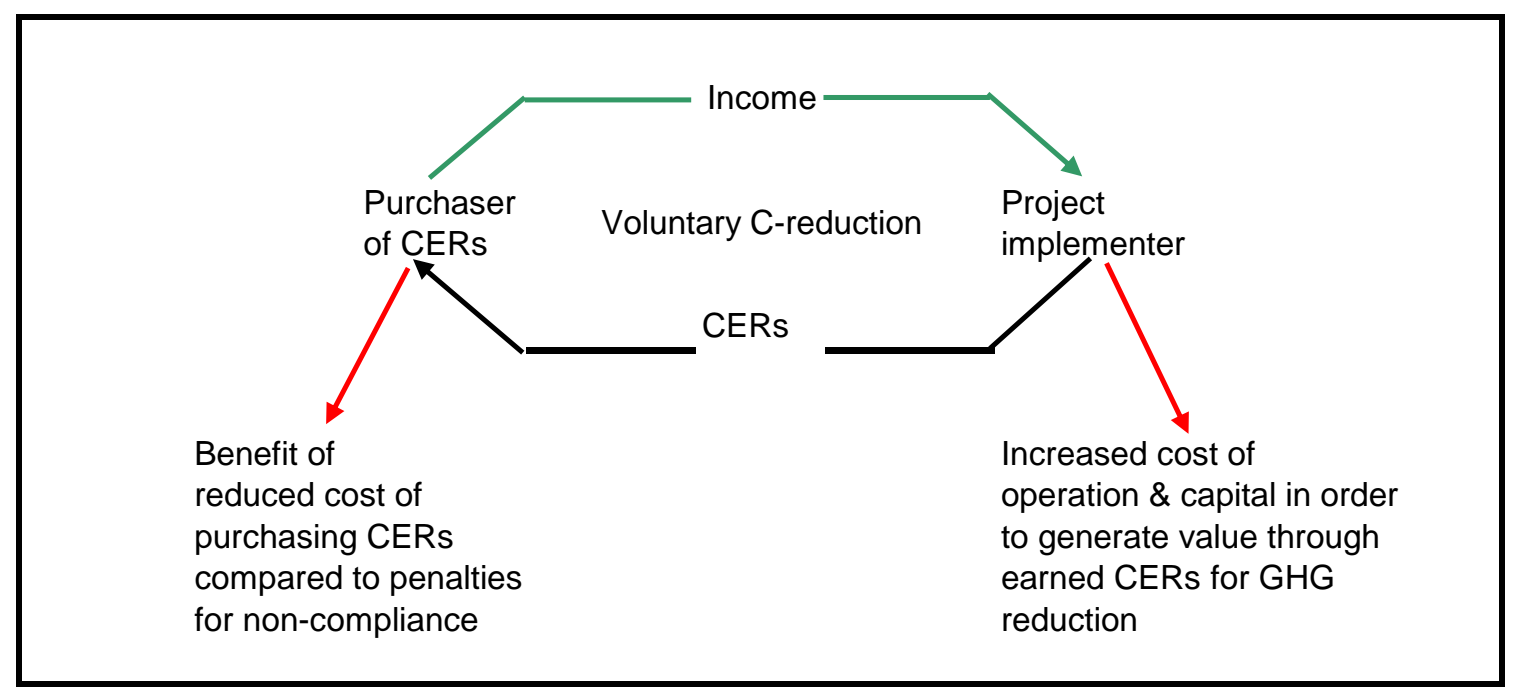

Figure 1: Logic to the existence of the Kyoto Protocol and CERs.

A company that implements a project to reduce its GHG emissions would have to spend additional capital and take on additional operating expenses in order to reduce its emissions and, in doing so, earn CERs. Companies that buy these CERs would therefore be able to offset their emissions by purchasing CERs at a lower cost than what they would have otherwise paid in penalties for exceeding their emissions limits. In terms of the Kyoto Protocol, cuts in the three major GHGs (accounting for roughly $75 \%$ of total GHG emissions), namely $\mathrm{CO}_{2}, \mathrm{CH}_{4}$ and $\mathrm{N}_{2} \mathrm{O}$, will be measured against a base year of 1990. Three other industrial gases, namely HFCs, PFCs and SF6 will also be considered. The protocol calls on rich countries (referred to as Annex1 countries) to take the initiative in controlling emissions (Waller-Hunter 2005). 
The Kyoto Protocol is therefore also in line with the holistic approach to environmental management embodied in ISO 14001, and has the potential for moving the global community toward economic development that is sustainable and restorative (Ritchie and Hays 1998: xxiii). However, it does lead to the question of how much GHG reduction will be achieved as a direct result of the Kyoto Protocol being put into action. Obviously if there is a big enough carrot for reducing GHG emissions, those that could benefit from this will do something.

This is exactly what the Kyoto Protocol aims to achieve. Through its different mechanisms, companies with GHG emissions lower than their permits allow could be encouraged to sell the balance of their allowed emissions to companies that exceed their emissions permit. The CDM mechanism of the Kyoto Protocol focuses on developing countries such as South Africa. It allows for companies to reduce their GHG emissions and thereby earn CERs. They can then sell these CERs (as some kind of tradable permit) to companies that exceed their GHG emissions allowance.

Similar to this suggestion, the European Union Emissions Trading Scheme (EU ETS), which came into force on 13 January 2005, started by giving EU countries "rights to pollution" or "emissions permits" based on their past pollution. These countries were given permits, which they could then trade - if they reduce GHG pollution they have an income stream from permits issued to them. However, if their emissions increase they could buy permits from someone else or pay penalties for emissions above their permit allocation.

CERs will work in the same way, except that they will have to be earned rather than given. A company will have to register a project, reduce their GHG emissions, and be able to prove by how much they have reduced their GHG emissions. In doing this there is no such thing as a "free ride". The biggest drawback of the EU ETS is that permits were given upfront. As a result, the price of these permits was reduced drastically when most EU countries submitted their 2005 emissions data, and the emissions were lower than expected. Hence, one of the key success factors of such a system would be measurement of GHG emissions both before and after the introduction of new technology.

\subsubsection{The Clean Development Mechanism Of The Kyoto Protocol}

Of specific importance to South African companies, the Kyoto Protocol established a Clean Development Mechanism. This mechanism specifically pertains to emissions in developing countries (which do not regulate GHG emissions or have less stringent limits than developed countries). When these non-Annex1 countries reduce their GHG emissions below their national emission limits they will earn credits for the lower-than-legislated emissions in the form of CERs. These CERs can then be sold to companies in Annex1 countries (which already regulate GHG emissions). Registering a CDM project is only possible if the emission reductions would not have occurred without the certified project activity, i.e. the emission reductions must be additional to reductions that would have occurred if there was no potential to earn CERs (Kyoto Protocol, Art. 12). An illustration of the CDM project cycle, taken from Stiles (2005c), is shown below in Figure 2. 


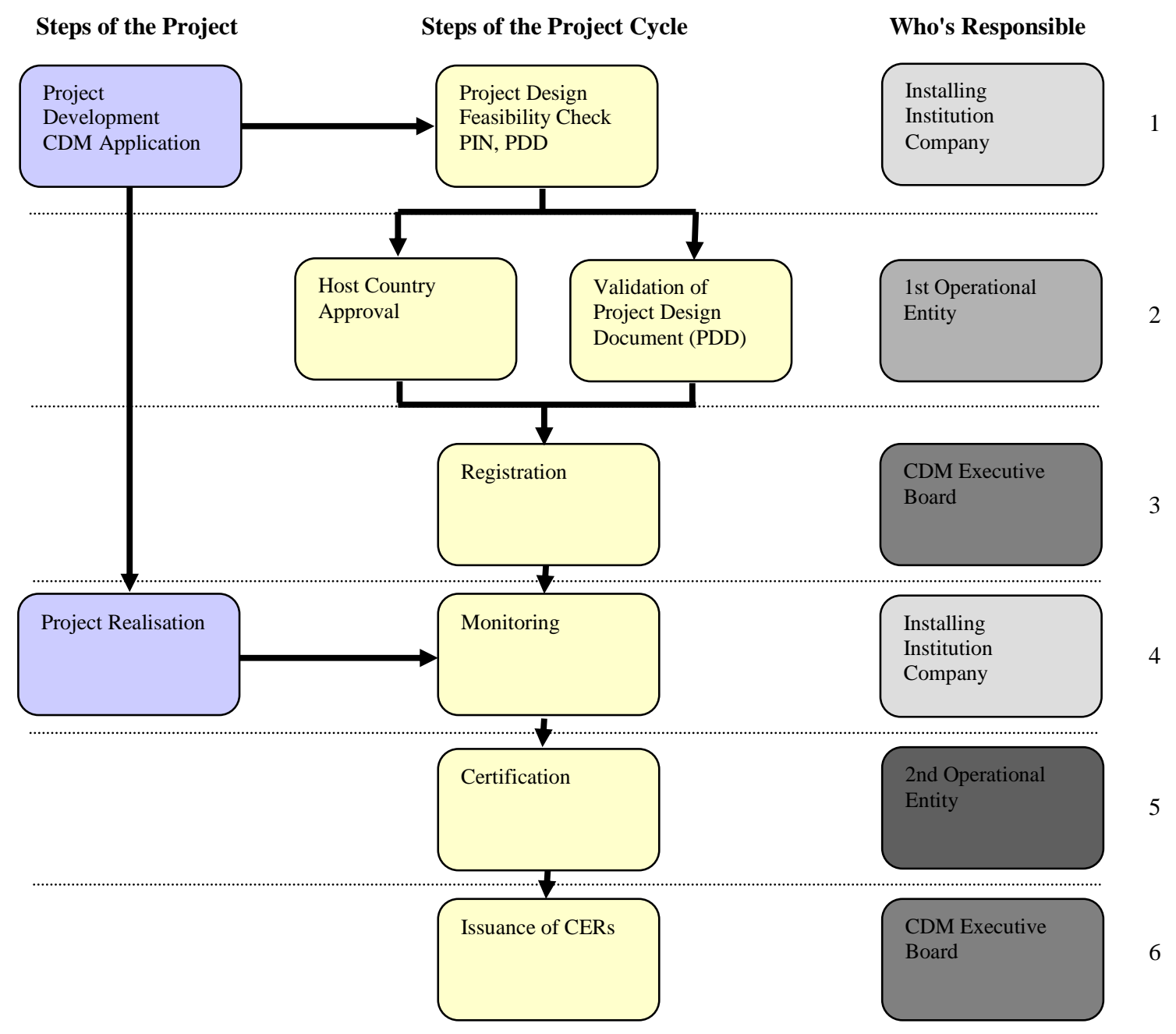

Figure 2: CDM project cycle (Source: Stiles 2005c).

Initially, a company has to assess the feasibility of a potential GHG emission reduction project, i.e. the amount of potential GHG emission reduction. A PIN (project idea note) is then submitted to the local authority to inform them of the intended project. As soon as the local authority has issued a letter of non-objection, the company or project proponent can continue with more detailed planning of the project. A PDD (project design document) is then developed according to the CDM guidelines to show how the emission reduction will be achieved. The PDD should include a baseline of current GHG emissions, the technology that will be used to reduce the GHG emissions, a detailed methodology of the project as well as an estimate of future GHG emissions after installation of the proposed technology.

The host country must then approve the PDD by issuing a letter of approval (LoA), whilst a registered DOE (designated operational entity) needs to validate the PDD. This should indicate that the proposed project is valid, that it should result in GHG emission reduction, and that it can be audited. The project must then be registered with the CDM executive board (EB). After the CDM EB has approved the project, the technology can be installed and monitoring of the achieved GHG emission reduction can commence. A second DOE (not the same one that validated the project initially) must then audit the actual monitoring data to verify what the actual GHG emission 
reduction achieved was over a certain period. Once verified, the CDM EB will issue CERs in line with the proven amount of $\mathrm{CO}_{2} \mathrm{e}$ emission reduction that was achieved.

Companies in Annex 1 countries can buy CERs in order to deduct this credit value from their actual emissions. In doing this they can potentially buy their reduction in emissions at a cheaper rate than what the penalties would have been for having emissions in excess of their permit conditions. This incentive was included because for those companies it might be very difficult and expensive to reduce their own emissions further. They could therefore invest in other developing countries (which is cheaper) to help them reduce their GHG emission and the overall result would still have an effect on the global GHG emissions (Kyoto Protocol, Art. 12).

Eventually all countries, even South Africa, will need to control their GHG emissions, although the wealthier, more industrialised countries (Annex1 countries) will have to lead climate protection efforts. These countries bear the historic responsibility for the problem and have greater financial resources enabling them to act (Baumert and Kete 2002). According to Sebitosi (2006), it is evident that the CDM market is becoming increasingly dynamic and it is expected to grow exponentially.

\subsection{South African Legislation Regarding GHG Emissions}

To date, air pollution regulation has been implemented through municipal and provincial permitting systems; however, on 19 February 2005 the President signed a new national air quality management bill. By contrast, greenhouse gases have until now received little attention from South African authorities. This is because, as so-called "global pollutants", they do not have a direct or measurable impact on the health of local populations (Stiles 2005b).

As a developing (or non-Annex1) country, South Africa has currently no commitments to reduce greenhouse gases under Kyoto Protocol, although it is likely that it will eventually have to implement some targets for GHG emissions under future versions of the Kyoto Protocol (Stiles 2005b). This means that any reduction in GHG emissions could currently be converted to "carbon-credits" and serve as a financial "lure" for South African companies to reduce their GHG emissions.

\subsection{Calculating Greenhouse Gas Emission Reductions}

For accounting purposes, all GHG emissions are related to a carbon dioxide equivalent $\left(\mathrm{CO}_{2} \mathrm{e}\right)$. In order to do this, the different gases are weighted by their respective global warming potential (GWP). GWP is a measure of the relative effect of a substance in warming the atmosphere, compared to the value of one for carbon dioxide $\left(\mathrm{CO}_{2}\right)$. The GWP values based on the effects of greenhouse gases over a 100-year time horizon for different GHGs are presented in Table 1 (Carstanjen 2004).

This would suggest that the global warming effect of methane is 21 times that of $\mathrm{CO}_{2}$, whilst the global warming effect of nitrous oxide is 310 times more than $\mathrm{CO}_{2}$. 
Table 1: GWP of greenhouse gases

\begin{tabular}{|c|c|c|}
\hline Greenhouse Gas & Chemical Formula & IPCC GWP 1995 \\
\hline Carbon Dioxide & $\mathrm{CO}_{2}$ & 1 \\
\hline Methane & $\mathrm{CH}_{4}$ & 21 \\
\hline Nitrous Oxide & $\mathrm{N}_{2} \mathrm{O}$ & 310 \\
\hline \multicolumn{3}{|l|}{ Hydrofluorocarbons (HFCs) } \\
\hline HFC-23 & $\mathrm{CHF}_{3}$ & 11,700 \\
\hline HFC-32 & $\mathrm{CH}_{2} \mathrm{~F}_{2}$ & 650 \\
\hline HFC-41 & $\mathrm{CH}_{3} \mathrm{~F}$ & 150 \\
\hline HFC-43-10mee & $\mathrm{C}_{5} \mathrm{H}_{2} \mathrm{~F}_{10}$ & 1,300 \\
\hline HFC-125 & $\mathrm{C}_{2} \mathrm{HF}_{5}$ & 2,800 \\
\hline HFC-134 & $\mathrm{C}_{2} \mathrm{H}_{2} \mathrm{~F}_{4}\left(\mathrm{CHF}_{2} \mathrm{CHF}_{2}\right)$ & 1,000 \\
\hline HFC-134a & $\mathrm{C}_{2} \mathrm{H}_{2} \mathrm{~F}_{4}\left(\mathrm{CH}_{2} \mathrm{FCF}_{3}\right)$ & 1,300 \\
\hline HFC-152a & $\mathrm{C}_{2} \mathrm{H}_{4} \mathrm{~F}_{2}\left(\mathrm{CH}_{3} \mathrm{CHF}_{2}\right)$ & 140 \\
\hline HFC-143 & $\mathrm{C}_{2} \mathrm{H}_{3} \mathrm{~F}_{3}\left(\mathrm{CHF}_{2} \mathrm{CH}_{2} \mathrm{~F}\right)$ & 300 \\
\hline HFC-143a & $\mathrm{C}_{2} \mathrm{H}_{3} \mathrm{~F}_{3}\left(\mathrm{CF}_{3} \mathrm{CH}_{3}\right)$ & 3,800 \\
\hline HFC-227ea & $\mathrm{C}_{3} \mathrm{HF}_{7}$ & 2,900 \\
\hline HFC-236fa & $\mathrm{C}_{3} \mathrm{H}_{2} \mathrm{~F}_{6}$ & 6,300 \\
\hline HFC-245ca & $\mathrm{C}_{3} \mathrm{H}_{3} \mathrm{~F}_{5}$ & 560 \\
\hline \multicolumn{3}{|l|}{ Perfluorocarbons (PFCs) } \\
\hline Perfluoromethane & $\mathrm{CF}_{4}$ & 6,500 \\
\hline Perfluoroethane & $\mathrm{C}_{2} \mathrm{~F}_{6}$ & 9,200 \\
\hline Perfluoropropane & $\mathrm{C}_{3} \mathrm{~F}_{8}$ & 7,000 \\
\hline Perfluorobutane & $\mathrm{C}_{4} \mathrm{~F}_{10}$ & 7,000 \\
\hline Perfluorocyclobutane & $c-\mathrm{C}_{4} \mathrm{~F}_{8}$ & 8,700 \\
\hline Perfluoropentane & $\mathrm{C}_{5} \mathrm{~F}_{12}$ & 7,500 \\
\hline Perfluorohexane & $\mathrm{C}_{6} \mathrm{~F}_{14}$ & 7,400 \\
\hline Sulphur hexafluoride & $\mathrm{SF}_{6}$ & 23,900 \\
\hline
\end{tabular}

Source: Carstanjen 2004

With specific reference to the explosives and fertilizer industry in South Africa, the companies that produce nitric acid $\left(\mathrm{HNO}_{3}\right)$ could potentially benefit financially if they were to register a project with the CDM whereby they employ new technologies to reduce the $\mathrm{N}_{2} \mathrm{O}$ emissions from these production units.

There are five nitric acid production units in South Africa, one of which is a high-pressure plant. The other four units are operating on dual pressure (medium pressure for the reaction section and high pressure for the absorption section). These production units use ammonia $\left(\mathrm{NH}_{3}\right)$ and air as raw materials, whilst $\mathrm{N}_{2} \mathrm{O}$ (a greenhouse gas) is emitted. According to Uhde design documentation (Maurer 2005) the $\mathrm{N}_{2} \mathrm{O}$ emissions from these production units differ, depending on the operating pressure of the specific unit. They give the following indications for $\mathrm{N}_{2} \mathrm{O}$ emissions:

Medium pressure plant (1.7 to 6 bar):

generates approximately $0.0074 \quad \mathrm{t} \quad \mathrm{N}_{2} \mathrm{O}$ or $2.17 \mathrm{t} \quad \mathrm{CO}_{2}$ High pressure plant (6.5 to 13 bar): equivalent per ton of $100 \%$ nitric acid produced; generates approximately $0.0097 \mathrm{t} \quad \mathrm{N}_{2} \mathrm{O}$ or 3.0 t $\mathrm{CO}_{2}$ equivalents per ton of $100 \%$ nitric acid produced.

The following example is used to illustrate how to calculate emission reductions. An emission of $0.007 \mathrm{t}$ $\mathrm{N}_{2} \mathrm{O}$ per ton $100 \% \mathrm{HNO}_{3}$ produced will be used. Using the GWP of 310 for $\mathrm{N}_{2} \mathrm{O}$ (as suggested by the IPCC) this relates to $2.17 \mathrm{t} \mathrm{CO}_{2} \mathrm{e}$ per ton $100 \% \mathrm{HNO}_{3}$ produced $(0.007 \times 310=2.17)$. If a production unit produces $225,000 \mathrm{t}$ $100 \% \mathrm{HNO}_{3}$ annually (three of the production units in South Africa have this capacity), it would therefore emit GHG to the equivalent of $488,250 \mathrm{t} \mathrm{CO}_{2} \mathrm{e}$ per year $(225,000 \times 2.17=488,250)$. If a nitric acid producer were to 
employ new technology that would destroy $70 \%$ of the $\mathrm{N}_{2} \mathrm{O}$ emissions, they would achieve GHG reduction of $341,775 \mathrm{t} \mathrm{CO}_{2} \mathrm{e}$ per year.

Once this reduction of GHG emissions is verified it would become a certified emission reduction that could be sold to Annex1 countries that emit more $\mathrm{CO}_{2} \mathrm{e}$ than what they are allowed to emit according to their emission permits (Waller-Hunter 2005).

When registering a CDM project, a baseline emission for the specific GHG would have to be determined before implementing new technology to reduce the GHG emission. To establish this baseline of current carbon emissions the company would need accurate records of emissions (Stiles 2005b). This in itself could prove to be quite expensive if these emissions were not measured before. Reliable instrumentation would have to be installed, calibrated regularly, and the data recorded continuously in electronic format. This data must then be stored in a safe place where it cannot be tampered with.

A company's GHG exposure is increasingly becoming a management issue in light of the heightened scrutiny by insurers, climate-related shareholder resolutions, and the emergence of environmental regulations/policies designed to reduce GHG emissions (Ranganathan and Bhatia 2003). It would therefore be prudent for any company to at least determine what their current GHG inventory is - they would need this in any case if they were to register a project to reduce GHG emissions.

Another important consideration when calculating the potential of a CDM project is that one needs to be conservative regarding the number of CERs that could be generated. This would ensure that potential income is not overstated. Karra et al. (2006) state that ABN AMRO, a carbon market specialist group, discounts the amount of CERs coming to market by modelling a realisation rate (currently 79\%). They do this because CDM projects to date have delivered lower than anticipated GHG emission reduction. They argue that this is because of over-optimism and time delays in project implementation.

\subsection{The Value of Certified Emission Reductions}

A number of factors determine the value of a CER on the market (Stiles 2005c):

- $\quad$ Bankability. CERs are the only carbon units that can be banked in one year and sold later. Other carbon units such as those earned in the EU ETS scheme have to be used in the year they are allocated. If a company in the EU emits less carbon or GHG than they are allowed to in a specific year, they cannot hold on to their EU ETS allocation and be allowed to emit more GHG in the next year. However, CERs that are bought in one year can be kept until the next year to offset the next year's GHG emissions. The theory is therefore that CERs should have higher value than other carbon units, because they can be banked, i.e. they do not have to be redeemed immediately.

- Sustainable development. Due to the characteristics of the CDM and the requirements of a CDM project, such a project should enhance a company's social responsibility profile. The host country has to issue a LoA before any CDM project can be registered. The host country's DNA has to ensure that the project complies with their sustainable development targets and, as a result, might require that a portion of the proceeds from CERs be spent on social development, etc.

- Delivery risk. Because CERs are still relatively new there is still a risk that a company that registers a project could eventually not implement it and therefore not earn any CERs. As a result, a company that wants to buy CERs to offset against their GHG emissions could take out an option to buy future CERs from another company that could potentially earn CERs. "This risk element is outweighing the inherent advantages to CERs as a carbon unit, resulting in CERs being traded at a discount on the carbon market. Once a spot market for CERs emerges with the issuance of the first credits of this type, this situation is expected to change to trading of spot CERs at a premium" (Stiles 2005c: 9).

It seems that the future outlook for EUA price has stabilised around $15 \mathrm{Euro} / \mathrm{CO}_{2} \mathrm{e}$ for the mid term. The main drivers of this price are the coal and gas prices, relative to each other, as these prices influence which source is used for energy generation and therefore affects the amount of GHG emissions from energy production. 
Referring to the example of possible reduced $\mathrm{N}_{2} \mathrm{O}$ emissions from nitric acid production units (Section 2.3), $341775 \mathrm{t} \mathrm{CO}_{2} \mathrm{e}$ reduction per year would result in $341775 \mathrm{CERs}$ being issued. If these could be sold on the spot market for Euro14, it would have a value of roughly R45m per year at a Rand-Euro exchange rate of 9.5. This is a significant potential benefit, and therefore producers can implement new technology to reduce their GHG emissions if they were to receive these credits.

Different technologies are available to reduce $\mathrm{N}_{2} \mathrm{O}$ emissions from nitric acid plants. It would therefore be prudent to do a NPV calculation for the project to determine which technology to use. The period for which these CERs could be earned is therefore important for the NPV calculation, whilst the implementation and operating cost of different technologies could then be compared against each other while also taking into account the amount of CERs that could be earned using the different technologies. It seems that the profitability of a CDM project would also be reduced, as profits would be taxed.

\subsection{International CDM projects}

As of mid-April 2007, 632 CDM projects were registered and another 77 were awaiting registration by the CDM Executive Board (Carstanjen 2007). This indicates that the UNFCCC has its systems in place to assist with CDM projects. More than 1000 projects have been rejected, indicating that it is not easy to get a project registered; a project needs to have definite and provable GHG emission reduction and needs to go through the cumbersome process of registration.

Of the 632 registered projects, fifteen are in Africa, and of these, only six are from South Africa. CERs have already been issued for projects that originated in the following countries: Brazil, India, Mexico, China, Chile, Republic of Korea, Papua New Guinea, Nicaragua, Peru, Sri Lanka, Malaysia, Argentina, Jamaica, Honduras and Guatemala. The following countries (or companies within these countries) have bought CERs from those that received CERs for projects reducing GHG emissions: Austria, Brazil, Canada, Denmark, Finland, France, Germany, Italy, Japan, Netherlands, Spain, Sweden, Switzerland, Britain and Northern Ireland.

Close to forty-five million CERs were issued through the CDM up to mid April 2007 (Carstanjen 2007). These were issued to more than 170 projects around the world that focused on reducing GHG emissions including $\mathrm{CO}_{2}, \mathrm{CH}_{4}, \mathrm{~N}_{2} \mathrm{O}$ and HFC. The first CERs were issued to a hydroelectric project in October 2005.

Early in 2005 a project to reduce $\mathrm{N}_{2} \mathrm{O}$ from an adipic acid plant in Paulinia, Brazil was submitted for registration by the CDM EB. Adipic acid is the main constituent of nylon and the proposed CDM project was to include the installation of a converter to convert $\mathrm{N}_{2} \mathrm{O}$ to nitrogen, thereby reducing GHG emissions. The project was successfully registered on 25 December 2005. As a result of this project the company managed to reduce the $\mathrm{N}_{2} \mathrm{O}$ emissions from their adipic acid plant by $1559 \mathrm{t}$ (for the two months of January and February 2007), compared to what the emissions would have been if not for such a project. Considering that the global warming potential of $\mathrm{N}_{2} \mathrm{O}$ is 310, this emission reduction translates to $483355 \mathrm{CO}_{2} \mathrm{e}$. In March 2007, 483355 CERs were issued to this project for proven GHG emission reduction. The other parties involved in the project (those that would potentially buy these CERs) are from the Netherlands, United Kingdom of Great Britain and Northern Ireland, and France.

\section{Presentation Of Results}

The results from the first portion of the research indicate why South African industry would be prepared to reduce their GHG emission and whether they would be able to benefit financially should they reduce their GHG emissions. Results were also used in an attempt to identify what all the factors are that would potentially affect the viability of CDM projects in South Africa.

The sample consisted of fourteen leading authorities: implementation experts, registered carbon credit traders, technology suppliers, persons currently responsible for the development of potential projects in South Africa, and EU government officials that offer their help to get CDM projects registered in South Africa. The respondents therefore have ample knowledge on the subject matter. The panel of experts used give balance to the 
research findings, as they include individuals with experience and expertise in all the different phases of CDM project implementation. The sample size was limited by the fact that the Kyoto Protocol was only ratified in 2005.

\subsection{Can South African Industry Benefit Financially When Reducing Their GHG Emissions?}

All the respondents indicated that South African industry would indeed be able to benefit financially if they were to reduce their GHG emissions but going the CDM route to register and implement a project to reduce GHG emissions is a cumbersome process. It is also requires a lot of resources - in the form of technical skills, knowledge regarding the CDM process, and financing.

In certain instances it might be possible for companies to reduce their operating costs when implementing a project to reduce their GHG emissions. This would apply in instances where new technology is both more cost effective to run and at the same time more environmentally friendly. If a business case can be made to switch to a technology that would reduce both costs and GHG emissions, this could result in reduced GHG emissions when such projects are implemented.

This would be the exception to the rule, however, and in most cases would only apply to new developments. In cases where new technology results in reduced GHG emissions for new plants, this cannot be seen as contributing towards reducing GHG emissions globally. Any new project that has GHG emissions is only adding to the global GHG emissions, unless it is implemented to replace an existing plant with high emissions.

It is also possible to reduce GHG emissions when employing new technology or alterations to an existing facility, without getting the additional benefit of increased operational efficiency or reduced costs. In such cases companies can register the project with the CDM under the Kyoto Protocol and earn CERs for proven reductions in GHG emissions. These CERs can then be traded (carbon trading) or sold to companies in Annex-1 countries, resulting in financial reward for voluntary GHG emission reduction.

By using the Clean Development Mechanism, South African industry could therefore register potential GHG reduction projects, and receive financial reward (in the form of tradable CERs) for the achieved GHG emission reductions.

\subsection{Why Would South African Industry Reduce Their GHG Emissions?}

The feedback from respondents confirmed that the reasons why South African industry would reduce their GHG emissions are consistent with those found in the literature that firms will do so if there is an incentive therein. The reasons for this can be grouped as follows:

i. $\quad$ Positive Public Relations (PR) - Category 1 incentive

South African industry would also, according to this research, attempt to reduce their GHG emissions to gain positive $\mathrm{PR}$ in an attempt to:

- $\quad$ Reduce shareholder pressure. With the increased awareness around global warming there is an "increased need to show to the outside world that your company is operating responsibly".

- Lower their carbon footprint. When reducing GHG emissions, companies will lower their carbon footprint and in doing so "reduce the impact of their operations on the environment".

- Gain additional marketing strength. When implementing projects to reduce GHG emissions, companies would be seen as taking a lead in the global attempt to reduce GHG emissions and fight global warming. Companies would then be able to use this as a marketing tool to sell products from "a company that cares for the environment".

- $\quad$ Satisfy their corporate social responsibility, by reducing their impact on their immediate environment.

- "Report on their triple bottom line" in terms of GHG emissions and energy efficiency as part of their sustainability reporting in annual reports. 
ii. $\quad$ Financial benefit - Category 2 incentive

South African industry could be rewarded financially for projects implemented specifically to reduce their "carbon footprint" or GHG emissions. Feedback from respondents is used to explain why these incentives would drive industry to implement GHG emission reduction projects. The additional financial benefit could, according to this study, be as a result of any of the following:

- When registering a CDM project to reduce GHG emissions from an existing operating facility, South African industry could receive additional revenue from CER sales.

- When registering and implementing a CDM project to reduce GHG emissions in South Africa, companies could get investment support from other companies/countries that would eventually purchase the CERs, or want to be seen as "assisting in the global attempt to reduce GHGs".

- A potential benefit of CDM project implementation is to "gain access to new 'cleaner' technology" i.e. technology transfer that would otherwise not be available due to its cost.

- When implementing new projects to reduce GHG emissions, industry could potentially reduce its operating costs. Although this would mean that such a project cannot be registered under CDM to earn CERs, the reduced GHG emissions would assist in reducing global carbon emissions.

- $\quad$ Projects aimed at reducing GHG emissions could also result in increased energy efficiency.

- $\quad$ Many industry players have realised that minimising environmental impacts is crucial for their long-term sustainability. It is therefore implied that a reduction in GHG emissions would give us the "opportunity to keep doing business for longer".

iii. Legislation - Category 3 incentive

It would be financially viable for South African industry to reduce their GHG emissions in line with legislation if:

- Local air emission legislation requires a reduction in GHG emissions. Only if there is an incentive (a penalty or negative incentive in this case) to reduce GHG emissions would South African industry reduce their GHG emissions.

- $\quad$ The Kyoto Protocol requirements for South Africa are such that GHG emissions must be reduced. It is "not impossible for the Kyoto Protocol to put GHG emission limits in place for South Africa" during the next phase of the protocol (post 2012).

- It is done unintentionally through the reduction of other legislated emissions or feasible projects.

\subsection{Which Factors Will Influence GHG Emissions From South African Industry?}

The feedback from all respondents was analysed and the factors that were considered to influence GHG emissions from South African industry are given in Table 2. These 46 factors are a combination of those identified from the literature reviewed and feedback from respondents. In order to understand how these factors would influence GHG emissions, they were used to construct a Fuzzy Cognitive Map (FCM). Where more than two thirds of the respondents agreed on the factor and its impact, the factor has been included in the FCM. 
Table 2: Effect of factors on the viability of CDM projects in South Africa

\begin{tabular}{|c|c|c|c|c|c|}
\hline $\begin{array}{l}\text { Effect of the following factors on the viability of } \\
\text { CDM projects in South Africa }\end{array}$ & $\begin{array}{c}\text { No } \\
\text { effect }\end{array}$ & $\begin{array}{c}\text { Positive } \\
\text { effect }\end{array}$ & $\begin{array}{c}\text { Negative } \\
\text { effect }\end{array}$ & $\begin{array}{c}>66 \% \\
\text { Agreement? }\end{array}$ & $\begin{array}{l}\text { Include in } \\
\text { FCM? }\end{array}$ \\
\hline Lack of GHG Legislation in SA & 3 & 10 & 1 & Yes & Yes \\
\hline Baseline of GHG Emissions in SA (Past emissions) & 3 & 10 & 1 & Yes & Yes \\
\hline Existing GHG Reduction Technology Available & 2 & 12 & 0 & Yes & Yes \\
\hline Approved Methodologies Available & 0 & 9 & 5 & No & Inconclusive \\
\hline Industry Drive to Reduce GHG & 2 & 10 & 2 & Yes & Yes \\
\hline Window of Opportunity & 2 & 10 & 2 & Yes & Yes \\
\hline CO2e Reduction Potential & 5 & 9 & 0 & No & Inconclusive \\
\hline Registration Costs & 3 & 0 & 11 & Yes & Yes \\
\hline Cost to Implement & 3 & 0 & 11 & Yes & Yes \\
\hline Capex Required & 3 & 1 & 10 & Yes & Yes \\
\hline Accuracy of Monitoring Equipment & 5 & 0 & 9 & No & Inconclusive \\
\hline Cost to Operate (including monitoring) & 4 & 0 & 10 & Yes & Yes \\
\hline Potential Financial Benefit & 2 & 12 & 0 & Yes & Yes \\
\hline Based in SA (potential CDM star) & 5 & 5 & 4 & No & No \\
\hline Efficiency of DNA & 4 & 6 & 4 & No & No \\
\hline Political Stability & 3 & 9 & 2 & No & Inconclusive \\
\hline Government and Industry Cooperation & 2 & 10 & 2 & Yes & Yes \\
\hline Industry knowledge of CDM & 3 & 1 & 10 & Yes & Yes \\
\hline Sustainable development criteria & 5 & 2 & 7 & No & Inconclusive \\
\hline No Success Stories in SA yet? & 3 & 0 & 11 & Yes & Yes \\
\hline EIA Requirements & 7 & 0 & 7 & No & Inconclusive \\
\hline Changes to Air Pollution Legislation in SA & 4 & 6 & 4 & No & No \\
\hline Post 2012 commitments (time-to-benefit) & 5 & 2 & 7 & No & Inconclusive \\
\hline Tax implication on CERs earned & 4 & 0 & 10 & Yes & Yes \\
\hline Availability of DOEs & 4 & 2 & 8 & No & Inconclusive \\
\hline Quality of implementation experts & 2 & 4 & 8 & No & Inconclusive \\
\hline Trading Experience in SA & 4 & 2 & 8 & No & Inconclusive \\
\hline Additionality requirements & 4 & 0 & 10 & Yes & Yes \\
\hline Nature of Potential projects (energy efficiency, etc.) & 11 & 2 & 1 & No & No \\
\hline Monitoring equipment availability & 11 & 1 & 2 & No & No \\
\hline Bureaucracy of CDM EB & 3 & 0 & 11 & Yes & Yes \\
\hline Efficiency of the CDM EB & 2 & 0 & 12 & Yes & Yes \\
\hline CER Market Volatility & 6 & 0 & 8 & No & Inconclusive \\
\hline CER Value & 6 & 8 & 0 & No & Inconclusive \\
\hline Rand-Dollar Exchange rate & 11 & 2 & 1 & No & No \\
\hline $\begin{array}{l}\text { Time required for project registration and } \\
\text { implementation (CDM complexity) }\end{array}$ & 2 & 0 & 12 & Yes & Yes \\
\hline Financing availability & 1 & 11 & 2 & Yes & Yes \\
\hline Perceptions of decision makers & 1 & 4 & 9 & No & Inconclusive \\
\hline Leadership from SA government and Industry & 2 & 3 & 9 & No & Inconclusive \\
\hline Availability of cheap coal resources & 3 & 2 & 9 & No & Inconclusive \\
\hline Availability of monitoring expertise in South Africa & 3 & 2 & 9 & No & Inconclusive \\
\hline Time to get response from DSM fund & 11 & 1 & 2 & No & No \\
\hline Lack of capacity at NER & 11 & 1 & 2 & No & No \\
\hline High SA grid emissions factor & 10 & 2 & 2 & No & No \\
\hline $\begin{array}{l}\text { Availability of so-called 'hot air' from Eastern } \\
\text { European } \\
\text { countries - especially Russia }\end{array}$ & 3 & 0 & 11 & Yes & Yes \\
\hline Lack of participation from the USA & 3 & 0 & 11 & Yes & Yes \\
\hline
\end{tabular}


A matrix (Table 2) was completed to indicate how the factors included in the FCM would impact on each other. The result of the consolidated feedback from respondents can be represented by the following FCM.

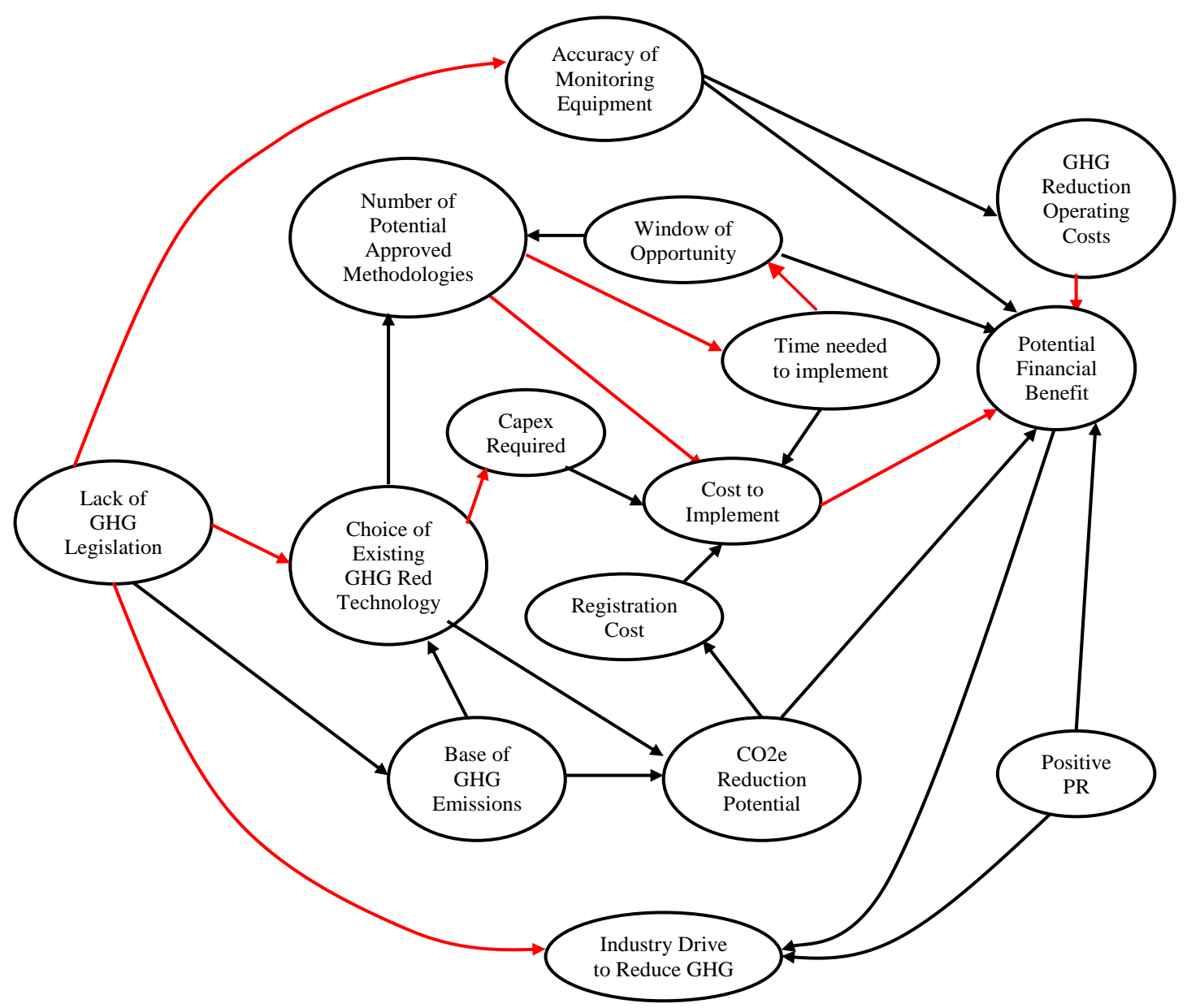

Figure 1: Final FCM without policy nodes.

Positive factors: These factors would drive South African industry to implement CDM projects.

- $\quad$ Existing GHG reduction technology available: South African industry has not spent vast amounts of effort on reducing GHG emissions in the past. As a result, the "current technology in use is not necessarily the least carbon intensive" and therefore alternative cleaner technology is available in many instances. The availability of alternative cleaner technology results in quicker CDM project realisation, as proven technology can be used.

- $\quad$ Potential financial benefit: Because CERs can be earned for voluntary GHG emission reduction, this "acts as a financial incentive for industry to implement CDM projects" to reduce GHG emissions. This gives project developers a "means to motivate the implementation" of such projects.

- $\quad$ Financing availability: According to the respondents there is "more than enough financing available for CDM projects".

- Approved methodologies available: The availability of approved methodologies results in a significant reduction in the time needed to get a CDM project developed and approved. Although applicability 
restrictions are in place, and require deviation requests if used slightly differently, this is "still much quicker than having to develop a new methodology" as part of a project.

- $\quad \mathrm{CO}_{2}$ e reduction potential: As all GHG emissions are related back to $\mathrm{CO}_{2}$, it makes some projects more lucrative, and this "acts as financial incentive" to implement CDM projects.

- Lack of GHG legislation: Respondents agree that this is the "starting point for CDM projects" in South Africa. The lack of GHG legislation is the reason that companies have not targeted GHG emission reduction in the past. As a result, the baseline of GHG emissions from South African industry is quite high and there is a huge potential to reduce these emissions.

- Industry drive to reduce GHG emissions: Some industries realise that they "will have to play catch-up if local GHG legislation was introduced, and they would rather make use of this opportunity" (whilst there is still some potential benefit) to implement GHG reduction projects.

- Window of opportunity: Due to the relatively small window of opportunity (as a result of uncertainty about the post-2012 regime) urgency is required from all parties involved.

- Government and industry cooperation: Although there is still room for improvement, the general consensus is that the "cooperation between government and industry has improved" over the last two years. Cooperation between these parties reduces friction and the time required to implement CDM projects.

Negative factors: These factors are those that would prevent industry from implementing CDM projects.

- $\quad$ Time required for project registration and implementation (CDM complexity): According to the respondents, the "time required to register a CDM project and have it approved by the CDM EB is often underestimated". In the South African context this process is further extended, as we do not yet have local examples of successful projects (from development, registration, implementation, verification of emission reduction and the subsequent issue of CERs).

- $\quad$ Efficiency and bureaucracy of the CDM EB: With the current efficiency of the CDM EB and the rigidity of the process, "things happen too slowly". Some respondents felt that the efficiency is improving, although "there is still a lot of room for improvement". The general feedback was that "unnecessary delays in the process and uncertainty regarding project approval increase the risk" involved with CDM projects especially if we consider that the current known window of opportunity is relatively small.

- Registration costs: Consensus is that the "high transaction costs are inhibitory" - these costs reduce the feasibility of projects and are especially hindering potential CDM project implementation from smaller players.

- Cost to implement: Once again, this "may be a hindrance to smaller players". The costs also largely dependent on the cost of available "cleaner" technology that can be introduced. The cost to implement the new technology is offset against the amount of potential GHG emission reduction that can be achieved, and therefore it is "crucial to use realistic future CER values" when doing the project feasibility.

- $\quad$ Availability of so-called 'hot air' from Eastern European countries - especially Russia: Hot air refers to large amounts of GHG emission reduction due to economic downturn. In countries like Russia, the economic downturn resulted in many industrial plants having to stop production. Currently the Kyoto Protocol and CDM allow the issue of CERs for such projects where GHG emission reduction is achieved only as a result of stopping operation of a particular plant. Many of the respondents argue that these 'free' CERs "result in saturation of the CER market". This will result in a reduction in the value of CERs and subsequent reduction in the potential benefit to project developers.

- Lack of participation from the USA: This factor currently has the same effect as "hot air". As the USA is currently not participating in the Kyoto Protocol (the USA is not a signatory), "the size of the carbon market is restricted".

- $\quad$ Capex and required operating costs: self explanatory

- $\quad$ Industry knowledge of CDM: Those parties who have been participating to date have been on a steep learning curve. The "concepts involved in the CDM process are easy to grasp", but developers often have too high expectations of the financial benefits when they are motivating potential projects. During the last two years, "a lot of effort has gone into building capacity" and most big industries now have adequate knowledge regarding CDM project implementation. It is often the smaller projects that run into capacity 
problems, and it would be greatly beneficial if government was to take the lead in helping these companies to develop their projects.

- $\quad$ Tax implication on CERs earned: As no South African project has yet received and sold any CERs, there is still "some uncertainty regarding the tax implications" on CERs traded. There is also some "concern regarding potential windfall taxes" on CERs earned.

- $\quad$ Accuracy of monitoring equipment: Local knowledge regarding the calibration and measurement of non$\mathrm{CO}_{2}$ greenhouse gases is limited, and would prove to be more costly.

- Additionality requirements: CDM projects compete with all other proposals in a company, and "the additionality clause is not appetising for any board".

\subsection{Fuzzy Cognitive Map}

In order to understand how the factors in Table 2 would influence GHG emissions, they were used to construct a FCM. The FCM is a mathematical model that describes the interaction between different factors that are linked. When an external factor is introduced (to impact on one or more of the other factors), the model iterates the interaction between concepts until equilibrium is reached. In a graphical illustration a FCM seems to be a signed directed graph (Stylios et al. 2001) - it acts as a mental model. The final FCM constructed for GHG emission reduction by South African industry is given below in Figure 4. It illustrates how the factors interact with each other, showing the dynamics of the system.

The arrows between two nodes represent the causal relationship between the two nodes (factors). A black (dark) arrow represents a positive relationship between the two factors; similarly, a red (light) arrow represents a negative relationship between the two factors. As a simple example: the constructed FCM indicates that an increase in the value of a CER would have the effect of increased potential benefit to a company implementing a CDM project. The increased potential benefit would in turn increase the likelihood that industry would increase its drive to reduce GHG emissions.

This is a very simplistic example, but as can be seen in Figure 4 there are many potential interactions between the different factors in the system (FCM). Triggers are therefore used to determine the resultant effect that any external factor would have on the system. 


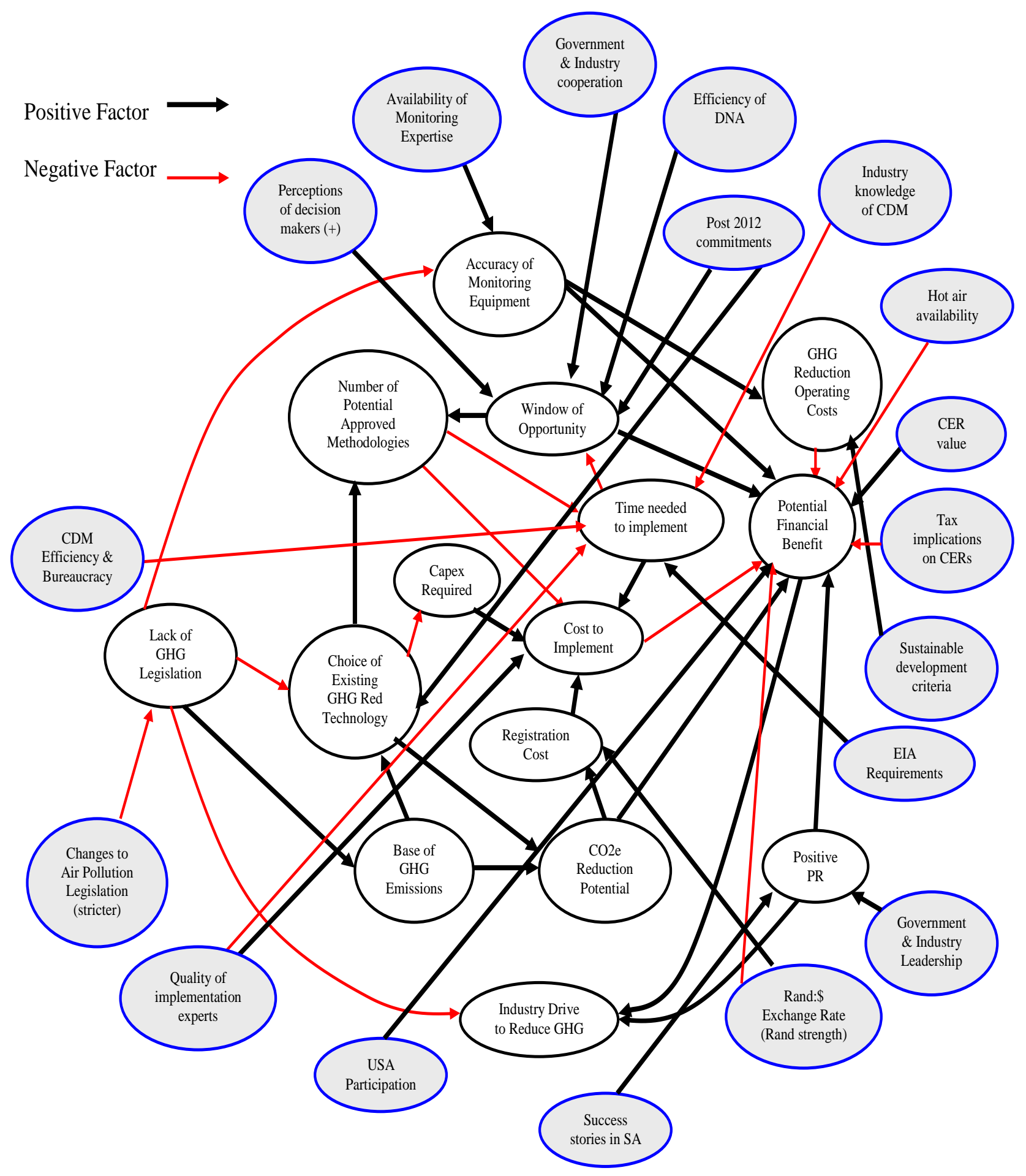

Figure 4: Final FCM with policy nodes, for GHG emission reduction by South African industry. 


\section{Conclusion}

The main purpose of this research was to determine whether the global efforts to reduce GHG emissions through the ratification of the Kyoto-Protocol, and more specifically the CDM, are likely to lead to a reduction in the amount of GHG emitted by existing South African industries in the next ten years. The rationale was that if there is financial benefit for South African companies then they would introduce technologies to reduce their GHG emissions. As the current legislation in South Africa does not specify any legal limits for GHG emissions it could be argued that a financial benefit is required to encourage companies to reduce their GHG emissions. According to the feedback from the respondents who participated in the research the following conclusions are reached:

- $\quad$ South African industry would only reduce GHG emissions if there is some sort of incentive for them to do so (e.g. positive PR, financial reward, or to avoid penalties if they exceed their legislated emissions).

- $\quad$ South African industry can indeed benefit financially if industries were to register CDM projects through which they would reduce their GHG emissions or carbon footprint.

- $\quad$ There are many factors that would impact on the viability of CDM projects by South African industry. Factors that would positively or negatively affect the viability of CDM projects were used to build a FCM to illustrate how the factors interact with each other. When external triggers are introduced, the FCM shows the dynamics of the system. Combinations of the following key factors would, according to the constructed FCM, drive industry to reduce GHG emissions:

$\circ \quad$ Stricter air emissions legislation to include GHG emission limits,

- CDM success stories in South Africa,

- Leadership from industry and government,

- USA ratifying the Kyoto Protocol,

- Improved GHG emissions monitoring expertise in South Africa,

$\circ \quad$ An increase in the value of CERs,

- Post 2012 commitments that allow South African industry to benefit for a longer period.

After analysing the current state of affairs, the following recommendations are offered to industry in developing countries that are considering the benefits under the Kyoto protocol:

- $\quad$ Start to measure the GHG emissions for current operations - industries have nothing to lose by understanding their current carbon footprints. In future, GHG would potentially be legislated and it would then be of great value if industries already understand their carbon inventories. There are also many examples of international companies that became more competitive when implementing projects after understanding their emissions inventories. A baseline of emissions will also be required for any CDM project - if these emissions are measured already, this will result in reduced project implementation time.

- Where possible, start to investigate options to reduce GHG emissions - future air emissions legislation may force industries to reduce these emissions. It will be prudent to also understand what the legal requirements (including EIA studies) would be if they were to implement a CDM project.

- Start to identify potential projects to reduce GHG emissions in current operations and carry out feasibility studies for these potential projects. Even if these initial studies are "matchbox"-type calculations, industry would understand what their earnings potential is from CDM projects.

- Develop and maintain healthy working relationships with authorities. This will ensure cooperation when required and could prove to reduce the time required for implementation.

- $\quad$ Start to build CDM capacity in-house. It is of great value if permanent employees are able to drive CDM project implementation - they understand the company better than any outside consultant, and would invariably be a "cheaper" resource. This is particularly important considering not many such skills are presently available.

- Start to pick "low hanging fruit", where there is a definite potential financial benefit to a company if it was to implement a project.

- If possible, use an international DOE for the initial validation of CDM projects. A local DOE can then potentially be used for annual certification - this should be a cheaper option.

- $\quad$ Show leadership in CDM capacity building and sharing of CDM success stories. 
This paper has shown that there are clear benefits in terms of greenhouse gas emission reductions to businesses in developing countries (non Annex 1) under the Kyoto protocol. It therefore makes sense both from a business and an environmental perspective and this was the very aim of using the market mechanism to bring about environmental change. This is a market still in its infancy but as more countries sign up to the Kyoto protocol or its successor so the need for businesses to consider its implications very seriously will increase.

\section{References}

1. Baumert, K. A. and Kete, N. (2002, last update April 2003) The United States, Developing Countries, and Climate Protection: Leadership or Stalemate, last accessed 1 August 2006, from http://earthtrends.wri.org//miscell/sitemap.php\#theme3

2. Carstanjen, H. (1992) United Nations Framework Convention on Climate Change, Framework Document, France.

3. Carstanjen, H. (2002) Understanding Climate Change: A Beginner's Guide to the UN Framework Convention and its Kyoto Protocol, In UNEP, France, pp. 1-4.

4. Carstanjen, H. (2004) The First Ten Years, Climate Convention Report, UNFCCC, Bonn France.

5. Carstanjen, H. (2006, last update 2006) CDM Statistics, last accessed March 2007, from http://cdm.unfccc.int

6. Carstanjen, H. (2007, last update April 2007) CDM Statistics, last accessed 25 April 2007, from http://cdm.unfccc.int/statistics/registration/NumOfRegisteredProjByHostPartiesPieChart.html

7. Houghton, J. T. (2004) Global Warming - The Complete Briefing, Third ed., Cambridge University Press, Cambridge.

8. Immink, H. (2006) 'Climate Change - Hard Times Ahead for Africa', Developing Africa, First Quarter 2006, pp 6-7, 10.

9. Karra, E., Mulder, G., Cornietje, R. and McBurnie, C. (2006, last update 26 June 2006) Carbon Markets Overview, last accessed 11 December 2006, from http://www.pointcarbon.com/CDM\%20\&\%20JI/category367.html

10. Kosko, B. (1993) Fuzzy Thinking: The New Science of Fuzzy Logic, First ed., New York.

11. Maurer, R. (2005) Nitric Acid, Uhde, Thyssenkrupp Technologies, Germany.

12. McClelland, C. (2005, last update April 2005) SA to Use Cleaner Fuels from 2006, last accessed June 2006, from http://www.southafrica.info/public services/citizens/consumer_services/leadedfuel010405.htm

13. Ranganathan, J. and Bhatia, P. (2003, last update June 2003) Accounting for Business Greenhouse Gas Emissions, last accessed July 2006 from http://earthtrends.wri.org//miscell/sitemap.php\#theme3

14. Ritchie, I., Hays, W. (1998) A Guide to the Implementation of the ISO 14000 Series on Environmental Management, Prentice-Hall, Englewood Cliffs, NJ, pp. xxiii.

15. Sebitosi, A.B. (2006) How Relevant to sub-Saharan Africa is the Kyoto Protocol?, Journal of Energy in Southern Africa, 17(1), pp 5-9.

16. Stiles, G. (2005a) Business and Climate Change: An Executive Briefing for South African Managers, Capacity Building Document, No. 1, CBLA, Rosebank, South Africa.

17. Stiles, G. (2005b) Business and Climate Change: Improving your Greenhouse Gas Profile, Capacity Building Document, No. 2, CBLA, Rosebank, South Africa.

18. Stiles, G. (2005c) Business and Climate Change: Selling Carbon Credits, Capacity Building Document, No. 3, CBLA, Rosebank, South Africa.

19. Stylios, C. D., Georgopoulos, V. C. and Groumpos, P. P. (2001) The Use of Fuzzy Cognitive Maps in Modelling Systems, Ohio University, Athens, USA.

20. Tyani, L., Matooane, L. and Mathenjwa, M. (2006) News Bulletin - Second Quarter Edition, DNA News Bulletin, June 2006, pp 1-2.

21. Tyani, L., Matooane, L. and Mathenjwa, M. (2005) 'News Bulletin - Monthly Edition', DNA News Bulletin, November 2005, pp 1-2.

22. Waller-Hunter, J. (2002) A Guide to the Climate Change Convention Process, UNFCCC, Bonn, France.

23. Waller-Hunter, J. (2005) Caring for Climate: A Guide to the Climate Change Convention and the Kyoto Protocol, UNFCCC, Bonn, France. 